\title{
Organic carbon inventories in natural and restored Ecuadorian mangrove forests
}

Mangroves can capture and store organic carbon and their protection and therefore their restoration is a component of climate change mitigation. However, there are few empirical measurements of long-term carbon storage in mangroves or of how storage varies across environmental gradients. The context dependency of this process combined with geographically limited field sampling has made it difficult to generalize regional and global rates of mangrove carbon sequestration. This has in turn hampered the inclusion of sequestration by mangroves in carbon cycle models and in carbon offset markets. The purpose of this study was to estimate the relative carbon capture and storage potential in natural and restored mangrove forests. We measured depth profiles of soil organic carbon content in 72 cores collected from six sites (three natural, two restored, and one afforested) surrounding Muisne, Ecuador. Samples up to $1 \mathrm{~m}$ deep were analyzed for organic matter content using loss-on-ignition and values were converted to organic carbon content using an accepted ratio of $1.72(\mathrm{~g} / \mathrm{g})$. Results suggest that average soil carbon storage is $0.055 \pm$ $0.002 \mathrm{~g} \mathrm{~cm}^{-3}(11.3 \pm 0.8 \%$ carbon content by dry mass, mean $\pm 1 \mathrm{SE})$ up to $1 \mathrm{~m}$ deep in natural sites, and $0.058 \pm 0.002 \mathrm{~g} \cdot \mathrm{cm}^{-3}(8.0 \pm 0.3 \%)$ in restored sites. These estimates are concordant with published global averages. Evidence of equivalent carbon stocks in restored and afforested mangrove patches emphasizes the carbon sink potential for reestablished mangrove systems. We found no relationship between sediment carbon storage and aboveground biomass, forest structure, or within-patch location. Our results demonstrate the long-term carbon storage potential of natural mangroves, high effectiveness of mangrove restoration and afforestation, a lack of predictability in carbon storage strictly based on aboveground parameters, and the need to establish standardized protocol for quantifying mangrove sediment carbon stocks. 


\section{Organic carbon inventories in natural and restored Ecuadorian mangrove forests}

2 Amanda G. DelVecchia ${ }^{1,2,3}$, John F. Bruno ${ }^{4}$, Larry Benninger ${ }^{5}$, Marc Alperin ${ }^{6}$, Ovik Banerjee ${ }^{1}$,

3 Juan de Dios Morales ${ }^{7}$

4 1Institute for the Environment, The University of North Carolina at Chapel Hill, Chapel Hill,

5 North Carolina 27599-3300 USA

$6{ }^{2}$ current address: Flathead Lake Biological Station, University of Montana, 32111 Bio Station

7 Lane, Polson, MT 59860

$8{ }^{3}$ corresponding author: amanda.delvecchia@umontana.edu

$9{ }^{4}$ Department of Biology, The University of North Carolina at Chapel Hill, Chapel Hill, North

10 Carolina 27599-3280 USA

$11{ }^{5}$ Department of Geology, The University of North Carolina at Chapel Hill, Chapel Hill, North

12 Carolina 27599-3315 USA

$13{ }^{6}$ Department of Marine Science, The University of North Carolina at Chapel Hill, Chapel Hill,

14 North Carolina 27599-3300 USA

$15{ }^{7}$ Colegio de Ciencias biologicas y ambientales, Universidad San Francisco de Quito, Cumbayá,

16 Diego de Robles y Vía Interoceánica, Quito, Ecuador

\section{Key Words}

18 aquaculture, blue carbon, carbon sequestration, carbon storage, loss-on-ignition, mangroves,

19 mangrove restoration, sediment accretion 
Introduction

The concentration of atmospheric $\mathrm{CO}_{2}$ has increased by forty-percent since the beginning

22 of the industrial revolution and continues to increase concentrations by 2 ppm annually (Dedysh,

23 Derakshani \& Liesack 2001; Le Quéré et al. 2012). As a result, we face a warming planet, rising

24 seas, changing precipitation patterns, and decreasing biodiversity (2012). Identifying effective,

25 efficient, and politically acceptable approaches to reduce the atmospheric concentration of $\mathrm{CO}_{2}$ is

26 thus one of society's most pressing goals. Reducing atmospheric $\mathrm{CO}_{2}$ via carbon sequestration -

27 transferring carbon to a safe biological or geological reservoir - is one such solution.

Terrestrial vegetation plays a key role in the global carbon cycle as both a sink and a

source of anthropogenic $\mathrm{CO}_{2}$ : total forest carbon uptake is $2.3 \pm 0.4 \mathrm{Pg} \mathrm{C} \mathrm{yr}^{-1}$ (Pan et al. 2011),

whereas the loss of vegetation via land use change adds $1.1 \pm 0.7 \mathrm{Pg} \mathrm{C} \mathrm{yr}^{-1}$. While terrestrial

forests as a whole are a net sink, tropical land use change emits $1.3 \pm 0.7 \mathrm{Pg} \mathrm{C} \mathrm{yr}^{-1}(\underline{\text { Pan et al. }}$

2011). Conservation of existing vegetation is therefore critical for preventing further carbon

emissions as well as for preserving carbon sequestration potential.

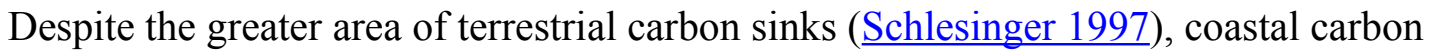

sinks have comparable global carbon sequestration values: total global carbon uptake in

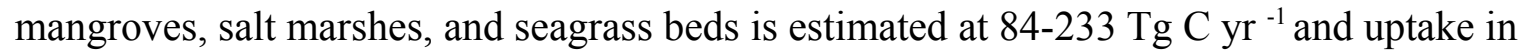
terrestrial systems is estimated at $180.8 \mathrm{Tg} \mathrm{C} \mathrm{yr}^{-1}$ (Kauffman et al.; Donato et al. 2011; McLeod

et al. 2011). In coastal ecosystems, high rates of uptake reflect high sediment accumulation rates ranging from 18 to $1713 \mathrm{~g} \mathrm{C} \mathrm{m}^{-2} \mathrm{yr}^{-1}$ (McLeod et al. 2011); organic carbon burial occurs as sediment is accreted vertically during periods such as the present, when sea level is rising

41 (Ellison 2008).

42 On an aerial basis, mangroves display some of the highest rates of carbon burial and storage 43 among vegetated habitats, sequestering 2.26 $\pm 0.39 \mathrm{Mg} \mathrm{C} \mathrm{ha}^{-1} \mathrm{yr}^{-1}$ and storing an estimated 1,023

$44 \mathrm{Mg} \mathrm{C} \mathrm{ha}^{-1}$ in aboveground and sediment stores combined (Kauffman et al.; Donato et al. 2011; 
45 McLeod et al. 2011). Their elaborate root structures slow the rate of water movement and

46 thereby create an environment conducive for the settling of clay and silt particles (Wolanski

47 1995; Young \& Harvey 1996). The carbon buried in these systems has been traced to not only

48 autochthonous sources such as litterfall, benthic macroalgae, and root decay, but also imported

49 sources such as seagrass and phytoplankton detritus, showing that mangrove forests provide

50 broad-scale sink benefits (Kristensen 2007; McLeod et al. 2011).

51 International carbon marketing systems such as REDD+ (Reduced Emissions from

52 Deforestation and Forest Degradation) place forest conservation projects in the context of the

53 global carbon offsets market. Such marketing requires accounting for the dynamic nature of

54 accumulation rates over temporal and geographic scales which are still not fully understood

55 (Alongi 2011). However, it is becoming increasingly clear that mangrove conservation (in a

56 carbon trading context) is more valuable for preventing carbon release from deforestation than

57 for continuously accounting for new sequestration (Kauffman et al.; Alongi 2011; Donato et al.

58 2012; Fourqurean et al. 2012).

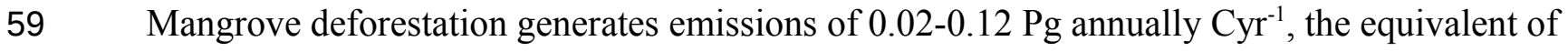

$602-10 \%$ of emissions from tropical deforestation despite the fact that global mangrove area is $<$

$611 \%$ of that of tropical forest area (Kauffman et al.; van der Werf et al. 2009; Giri et al. 2011;

62 Donato et al. 2012; Le Quéré et al. 2012). Nearly half of the world's mangroves forests have

63 already been cleared, and the recent deforestation rate is roughly 1-3\% annually (Alongi 2002;

64 Bouillon et al. 2008; Donato et al. 2011). Mangroves are usually cleared for development or

65 conversion to aquaculture (Alongi 2002). Upon clearing, both the aboveground biomass and

66 sediment carbon stores are disturbed and/or aerated, increasing microbial activity (Granek \&

67 Ruttenberg 2008; Couwenberg, Dommain \& Joosten 2010; Lovelock, Ruess \& Feller 2011;

68 Pendleton et al. 2012).

69 Though conservation of these ecosystems could be incentived by recognizing both their 
continuing sink potential and the adverse effects of deforestation via carbon release, the

71 application of existing information to conservation initiatives is limited by a lack of empirical

72 data. Most carbon storage and sequestration studies are from Florida, China, the Indo-Pacific,

73 Australia, and the Brazilian coastline, despite global distribution of mangroves on coastlines

74 between 0 and 30 degrees latitude(Fujimoto et al. 1999; Cebrian 2002; Chmura et al. 2003).

75 Mangrove storage and sequestration estimates in South America, especially on its Pacific coast,

76 have been extremely rare thus far.

77 In addition, methodological discrepancies have led to significantly different results which are

78 difficult to interpret. Carbon storage and sequestration quantification is limited by a lack of

79 concurrent data on depth, bulk density, carbon concentration, and sediment accumulation rates

80 (Kauffman et al.; Alongi 2011; Donato et al. 2011). Finally, though the value of mangrove

81 conservation can be inferred from previous observations of their natural state, little work has

82 addressed the effectiveness of restoring these ecosystems in terms of carbon storage and

83 sequestration (Laffoley \& Grimsditch 2009).

84 The purpose of the study was to understanding how mangrove carbon storage varies with

85 environmental context. Primarily, we asked how soil carbon standing stocks vary based on forest

86 structure, locations within mangrove patches (defined here as continuous stands of mangroves),

87 and patch land use history. Additionally, we examined how carbon concentration varies with soil

88 depth in a given location and how these concentrations may be most accurately determined. We

89 used these estimates to analyze the carbon storage efficiency of restoring mangroves in sites

90 previously cleared for shrimp farming, and introducing mangroves to replace native vegetation.

\section{Methods}

92 Study Sites

93 We surveyed the forest and collected soil cores at six sites in coastal Ecuador. The sites 
94 are located between $0^{\circ} 32^{\prime} \mathrm{N}$ and $0^{\circ} 38^{\prime} \mathrm{N}$ and surround the island of Muisne in the Esmeraldas

95 province of Ecuador. This area is unique for its community-driven focus on conservation and

96 successful restoration of mangrove forests. We selected three natural sites, two restored sites, and

97 one afforested site that have similar geography and comparable patch sizes. All sites are mainly

98 monocultures of red mangroves (Rhizophora mangle) with scattered white (Laguncularia

99 racemosa) and black mangroves (Avicennia germinans) at the fringes.

100 We determined site histories using a combination of unpublished maps and land use

101 documents from the Jatun Sacha Foundation (a local non-profit conservation organization),

102 interviews with local residents and property owners, and official maps from Ecuador's Instituto

103 Geografico Militar (Andres Leith, pers. comm). The natural sites (Nat A, Nat B, and Nat C) are

104 located in mangrove forest that has been undisturbed for at least three decades (and likely much

105 longer). The restored sites (Rest A and Rest B) were predominantly mangrove forest until the

106 1980's, at which point they were dredged, diked, and filled for use as shrimp farms until the time

107 of restoration in 2003 (Rest A) or 2000-2002 (Rest B). These sites, having been re-established by

108 planting of red mangrove propagules gathered from existing populations, are characterized by

109 smaller trees with more uniform ages. The afforested site (Aff) is an area that was converted

110 from halophytic ferns to mangrove in 1993.

111 At each of these sites, we established six plots using a random selection of coordinates.

112 For each plot, we took forestry surveys and outlined a 1x1 m quadrat that could be used to take

113 replicate soil core samples. We then mapped site coordinates and used Google Earth to measure

114 the shortest straight-line distance to the mangrove patch edge to determine a rough estimate of

115 distance to the estuarine shoreline. We estimate a measurement error of approximately $30 \mathrm{~m}$ on

116 coordinate and distance measurements due to; a) the difficulty of obtaining satellite signals from

117 within the dense mangrove canopy and b) inaccuracy in the simple straight line measurements

118 made using Google Earth. 


\section{Forestry Surveys}

120 In order to test whether sediment carbon storage varied with forest composition and

121 density, we collected and analyzed forestry data using the protocol outlined in the GOFC-GOLD

122 sourcebook published by REDD (Reduced Emissions from Deforestation and Forest

123 Degradation) (Pearson, Walker \& Brown 2005). At each plot, we first delineated a 2x2 m

124 quadrat, in which we used a diameter tape to measure the $\mathrm{DBH}$, or 'diameter at breast height'

125 (height $1.3 \mathrm{~m}$ ) of each tree. In cases where the prop roots typical of $R$. mangle extended above

126 breast height, we took the diameter at $30 \mathrm{~cm}$ above the uppermost root connection to the main

127 trunks (Komiyama, Poungparn \& Kato 2005). Multiple trunks were individually measured for

128 use in allometric equations but noted as the same tree in tree density calculations (Clough, Dixon

129 \& Dalhaus 1997). As per calculations recommended by the GOFC-GOLD Sourcebook, we used

130 a nested plot design to measure total forest biomass. If any DBH exceeded $5 \mathrm{~cm}$, the $2 \times 2 \mathrm{~m}$ was

131 then extended to a $7 \times 7 \mathrm{~m}$ plot, in which we followed the same process for all trees with at least

132 one trunk $>5 \mathrm{~cm}$ in DBH. Finally, if any trees in this plot exceeded $25 \mathrm{~cm}$ in diameter, we

133 extended the quadrat to $25 \times 25 \mathrm{~m}$ and measured all trees with diameters $>25 \mathrm{~cm}$.

134 We used DBH data to derive aboveground biomass estimates using the species-specific

135 allometric equations recommended by (Komiyama, Ong \& Poungparn 2008):

\section{Rhizophora mangle}

137 (1) $\mathrm{W}_{\text {top }}=0.178(\mathrm{DBH})^{2.47}, \mathrm{r}^{2}=0.98, \mathrm{n}=17$

138 Avicennia germinans

139 (2) $\mathrm{W}_{\text {top }}=0.140(\mathrm{DBH})^{2.54}, \mathrm{r}^{2}=0.99, \mathrm{n}=21$ 
141 (3) $\mathrm{W}_{\text {top }}=0.209(\mathrm{DBH})^{2.24}, \mathrm{r}^{2}=0.99, \mathrm{n}=17$

142 These equations accounted for all aboveground biomass. Estimates of biomass density at 143 the hectare scale were calculated by scaling up the $2 \times 2,7 \times 7$, and $25 \times 25 \mathrm{~m}$ quadrat biomass and 144 tree totals to hectare totals.

\section{Soil Core Collection}

146 We collected two soil cores from each of the 36 plots using a $6.69 \mathrm{~cm}$ inner-diameter $\mathrm{x} 1$ 147 m length stainless steel core tube with a sharpened edge. The tube was equipped with a rubber

148 piston held by rope at the top of the soil surface (or water surface if the soil was submerged) to 149 minimize compaction as the core tube was pushed down. The piston was maintained in place 150 relative to the tube as the core was retrieved from the soil, ensuring soil retention. When the tube

151 reached the soil surface, a rubber plug was inserted into the bottom of the tube.

152 The core was sectioned in the field by propping the tube on a wooden dowel, removing

153 the upper rubber piston, and pushing down on the core barrel to extrude the soil upward. We

154 sampled $1 \mathrm{~cm}$ sections at $6 \mathrm{~cm}$ resolution, discarding the uppermost $5 \mathrm{~cm}$ as litter fall. Samples

155 were removed using a stainless steel knife run along the top edge of the core tube. We discarded

156 a $5 \mathrm{~mm}$ rind from each section to remove soil that may have been mixed due to friction along the

157 wall of the core tube. Soil samples were double sealed in Whirl-paks ${ }^{\circledR}$ and frozen.

$158 \underline{\text { Soil Analyses }}$

159 To obtain bulk soil density, we removed visible root material; decaying plant matter and 160 dead wood were left in the sample. Root removal is necessary to measure soil density, but results 
161 in underestimating organic carbon inventories, as the woody root matter accounts for an average

162 of $8.1 \%$ of the sample volume in samples where roots was removed. After root removal, we 163 transferred soil samples to tared aluminum foil boats, dried them at $105^{\circ} \mathrm{C}$ for 12 hours, and

164 reweighed each sample. The drying time was validated by drying a subset of 67 samples for 12 ,

16524 , and 48 hours; relative differences in mass between 12 hours and each of the longer durations

166 were $0.2 \%$ and $0.3 \%$, respectively, so 12 hours was chosen as an acceptable drying time. Bulk

167 soil density was calculated as the mass of dry soil per volume of bulk soil. Bulk soil volume was 168 calculated for each sample using a $5.59 \mathrm{~cm}$ diameter (after discarding rind) and measured core

169 segment height, with the volume of the removed root matter subtracted (root matter volume was 170 measured to a precision of $0.2 \mathrm{~cm}^{3}$ using water displacement).

171 One replicate core from each plot was processed exclusively for loss-on-ignition (LOI).

172 Dried samples were ground and homogenized using a mortar and pestle until the material could 173 pass through a $2 \mathrm{~mm}$ mesh. We transferred the entire dry sample to a tared crucible to burn at $174500^{\circ} \mathrm{C}$ for 12 hours, as recommended by Wang et al. (2011) for non-marine sediments. The 175 reported precision of the LOI method depends on soil type, but is always $< \pm 15 \%$ of the 176 measured value (Wang et al. 2011). We did not measure LOI reproducibility because the entire 177 sample was combusted.

178 We tested the traditionally assumption that in general, organic matter (represented by 179 LOI) is comprised of 58\% organic carbon, yielding a 1.72 conversion factor (Allen 1974). 180 Despite the likelihood that these assumptions provide only approximations, the 1.72 conversion

181 factor has been used to derive global estimates of mangrove carbon storage and sequestration 182 (Chmura et al. 2003; Duarte, Middelburg \& Caraco 2005; McLeod et al. 2011). We examined 183 this assumption by sub-setting samples carbon analysis.

184 The second replicate core from selected plots - two natural, two restored, and two 185 afforested cores were chosen arbitrarily_ was used for total organic carbon (TOC) analysis using 
186 a Carlo-Erba Elemental Analyzer. These samples were dried, ground, and homogenized

187 following the procedure described above for LOI. Triplicate 7-10 $\mathrm{mg}$ aliquots of each dried and 188 homogenized sample were weighed into tared tin boats and fumed with gaseous $\mathrm{HCl}$ to remove

189 inorganic carbon. We followed the method of Hedges and Stern (Hedges \& Stern 1984) except

190 that we used tin rather than silver sample boats. Tin reacts with $\mathrm{HCl}$ vapor to form $\mathrm{SnCl}_{2}$,

191 possibly affecting the tare and causing the boats to become brittle. The reported precision of the

192 TOC method is $\pm 1 \%$ of the measured value (Hedges and Stern 1984); however, precision of our

193 TOC analyses averaged $\pm 18 \%$ (range: $2-45 \%$ ), probably related the use of tin boats. This has

194 limited impact on our organic carbon inventories, since they are ultimately related to LOI, which 195 has similar reproducibility. The remaining soil from the second replicate core was analyzed for 196 LOI to provide paired data for forming the TOC-LOI calibration equation.

197 Statistical Analyses

198

We averaged sample measurements hierarchically to analyze on the levels of plot, site, and classification. Whenever possible, we averaged measurements by depth from both replicate 200 cores in each plot $(\mathrm{n}=36)$, and otherwise used the measurements from a single core $(\mathrm{n}=8)$. In 201 cases where we looked at site-specific and classification-specific differences, we first averaged 202 plot measurements to compute averages by depth and/or carbon standing stocks. We took carbon 203 concentration to be the product of individual sample bulk density and \%TOC values.

204 We used the R platform for all statistical analyses. We used the caTools package to 205 compute integrated loess curves ( $\operatorname{span}=0.5$ ) over the maximum depth interval per set of plot 206 averages to calculate total carbon standing stock per unit area per plot. All integrations began at 5 $207 \mathrm{~cm}$ of depth rather than at surface level to avoid the uncertainty introduced by extrapolation, so 208 we may have underestimated the carbon standing stocks. We separately integrated all plots with 
209

210

211

212

213

214

215

216

217

218

219

220

221

222

223

224

225

226

227

core measurements $>70 \mathrm{~cm}$ in depth from 5 to $70 \mathrm{~cm}$ to compare sites and classifications without

the confounding effect of varying core lengths; we term these integration results corrected

carbon stocks.

We used linear mixed effects models to assess the effects of site, land history

classification, total aboveground biomass, tree density, species composition (percent trees which

were red mangroves versus white or black) and distance to estuarine shoreline on the corrected

carbon stocks using the NLME package in R. The Akaike information criterion (AIC) was used

to determine the best models and parameters using random components for site and classification

values. Additionally, we used a Welch Two Sample t-Test to compare natural and restored site

standing stocks using the corrected measurements (up to $70 \mathrm{~cm}$ and no further).

\section{Results}

\section{Aboveground Biomass (AGB) and Tree Density}

Natural sites and the afforested site had significantly higher AGB and significantly lower tree density than the restored sites (Fig. 2; Table 1). As a mangrove forest matures, the trunks get larger and more dispersed, with larger root boles which overlap in the areas between trees.

Similar AGB and tree density in afforested and natural sites suggests that 20 years is sufficient for a mangrove forest in this region to reach maturity; lower AGB and higher tree density at the restored sites suggests that the mangrove forest is still maturing 10 years after restoration. AGB for all sites at the low range of previous estimates across all latitudes (Alongi 2002). 
inventories. The mass lost through combustion includes the non-mineral component of organic

231 matter as well as lattice water in clays and other soil components that are volatile at high temperature; oxygen may be incorporated if nonvolatile oxides form during combustion. LOI is sometimes converted to TOC using the van Bemmelen factor $(\mathrm{TOC} / \mathrm{LOI}=58 \%)$, but numerous

234 studies have shown that the TOC/LOI ratio can range over a factor of two (Howard \& Howard 235 1990) and depends on soil type.

236 Our results suggested a strong linear correlation between $\%$ lost-on-ignition and \% total organic 237 carbon content found via carbon analysis (Fig. $\left.2, \mathrm{R}^{2}=0.89, \mathrm{p}<0.001\right)$ : TOC $(\%)=0.87$ LOI $(\%)-$ 238 5.8. The TOC/LOI ratio (87\%) and the y-intercept of LOI vs. TOC suggest that these soils 239 contain almost $7 \%$ structural water or minerals that are volatile at $550 \mathrm{C}$. Howard and Howard 240 (1990) found that the TOC vs. LOI linear regression yielded the highest y-intercept (5.64) for

241 gley sediments high in clay content (mean 21.9\%). This equation had a linear coefficient of 1.52 242 and an $\mathrm{R}^{2}$ of $52 \%$.

The coefficient of variation for our TOC analysis averaged $\pm 18 \%$ (range $4 \%$ to $45 \%$ ). The

244 reproducibility is well below the analytical precision under optimal conditions $( \pm 2 \%)$ and may

245 reflect instrumental variability or heterogeneity in the sediment. We therefore present a range of

$246 \%$ TOC values calculated using both the van Bemmelen factor and our conversion equation.

\section{Carbon Concentrations}

As found in previous studies (Kauffman et al.; $\underline{\text { Avnimelech et al. 2001; Donato et al. }}$

249 2011), our results suggested an inverse relationship between \%total organic carbon (\%TOC, mass

250 sediment organic carbon per mass sediment) and bulk density ( $\mathrm{g} \mathrm{cm}^{-3}$, mass dry sediment per

251 volume wet sediment): 
Overall across all natural and restored sites and depths, median TOC content was found to

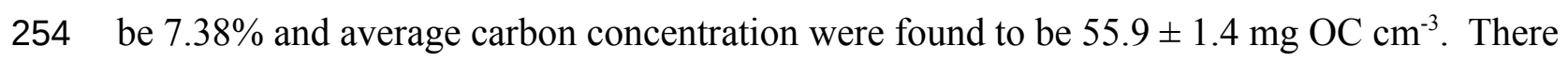

255 appears to be no consistent change in \%TOC in either classification over the $1 \mathrm{~m}$ depth interval

256 (Figure 5). Though a slight decrease is noted in both site classifications from 80-100 cm depth,

257 deeper samples would be necessary to verify whether or not this is a continuous pattern. A

258 significant peak is uniquely present in the \%TOC content of the restored sites at approximately

$25930-60 \mathrm{~cm}$. The same peak holds when measurements are converted to carbon concentrations

260 (Figure 6). After measurements were converted to corrected carbon standing stocks, results

261 suggested that restored sites contained more sediment carbon $\left(411.6 \pm 27.9 \mathrm{Mg} \mathrm{C} \mathrm{ha}^{-1}\right)$ than

262 natural sites $\left(365.3 \pm 23.8 \mathrm{Mg} \mathrm{C} \mathrm{ha}^{-1}\right)$, these differences were not statistically significant (two-

263 tailed t-test 0.22 ).

264 Analysis of carbon standing stock using the linear mixed effects models suggested that, as

265 predicted, core length is highly significant $(\mathrm{p}<0.001)$ as a predictor of the total carbon standing

266 stock. No other variable was found to significantly improve the model, e.g., we found no clear

267 evidence of a relationship between distance to estuarine edge, species composition, or site

268 classification and standing stock, even when coordinates were included. Aboveground biomasses

269 and belowground standing stocks by site are presented in Table 1. A Mantel test indicated there

270 was a significant effect of location (UTM coordinates) on total sediment carbon standing stock (p

$271=0.05)$ but not on total aboveground biomass $(\mathrm{p}=0.89)$ but the addition of coordinates to the

272 linear mixed effects models had no effect.

\section{Discussion}

\section{Carbon Standing Stocks}



mangroves, suggesting that carbon standing stock in ten year old restored mangroves with

277 significantly less aboveground growth is approximately equivalent to stock in natural mangroves

278 that are likely at least 40-50 years old (Alongi 2002). Additionally, carbon concentration did not

279 vary with depth between $5 \mathrm{~cm}$ and up to $1 \mathrm{~m}$, suggesting that significant decomposition does not

280 occur from the time that the organic carbon is buried until at least the time that this depth

281 represents. This finding was concordant with that of Donato and colleagues (2011), who

282 concluded that changes in each of these parameters occur deeper than approximately $1 \mathrm{~m}$ in

283 depth. Based on published averages of mangrove sediment accretion rates (Alongi 2012;

284 Breithaupt et al. 2012) our measured top $90 \mathrm{~cm}$ of sediment likely represent $280 \pm 80$ years $(95 \%$

285 C.I.) of sediment / carbon accumulation.

286 We also found that carbon standing stock up to $1 \mathrm{~m}$ in depth is strongly correlated with

287 core length. Though this relationship would be expected under the simple assumption that more

288 sediment analyzed implies more carbon to be found, our identification of the relationship

289 emphasizes two points regarding future quantification of globally distributed mangrove stocks.

290 The first is that shallower cores may be useful in calculating carbon stocks up to $1 \mathrm{~m}$ in depth,

291 potentially validating extrapolation (to a limit) of studies such as those presented by Chmura et

292 al. (2003) which included measurements from up to $0.5 \mathrm{~m}$ depth. The second point is that

293 calculation of carbon stocks requires an understanding of soil depth as it varies in mangroves

294 globally, as slight changes in this depth measurement have strong implications for the calculation

295 of total sediment carbon stock. Studies which address overall sediment depth have to this point

296 been rare, as can be seen in several meta-analyses and recommendations for future research

297 (Kauffman et al.; Chmura et al. 2003; Laffoley \& Grimsditch 2009; Donato et al. 2012).

298 Additionally, we found that neither forest structure and composition nor distance from the 299 seaward edge are significant predictors of carbon standing stock up to $70 \mathrm{~cm}$ in depth. Though 
300 the clear differences in aboveground biomass with forest maturity likely influence immediate

301 accretion and litterfall rates, the dynamic nature of these forests (i.e. tendency for scour and/or

302 deposition during storm surges) would prevent us from detecting those effects in measurements

303 of carbon storage over long time periods without intensive sampling.

\section{Natural versus Restored and Afforested Site Parameters}

305 We found that natural, restored, and afforested mangrove sites are equally important in

306 terms of current carbon standing stock, emphasizing the value of preservation of relatively young

307 forests as well as old growth stands--disturbance of either classification would aerate similar 308 quantities of sediment organic carbon. We found a $12.6 \%$ higher mean value for restored sites

309 than natural sites (365 $\left.\mathrm{Mg} \mathrm{C} \mathrm{ha}^{-1}\right)$, despite the clearly later successional stages of the natural sites.

310 This implied that mangrove restoration of shrimp farms is effective at restoring ecosystem

311 function, at least in terms of carbon sink potential seen in the decade post-restoration. This

312 finding contradicts that of Osland et al. (2012) (Osland et al. 2012), who found lower rates of

313 carbon storage in restored mangroves.

314 The higher mean carbon stock of restored sites appears to be due to a peak in

315 concentrations at approximately $30-60 \mathrm{~cm}$ deep. Because the same peak was not present in the

316 afforested site profile, it could represent a relic of the shrimp farm history of the restored sites.

317 Higher concentration values could result from shrimp carcasses, 'fertilizer', or feces that

318 accumulated during the farming period and were buried when the mangroves were replanted and

319 began to accrete sediment. Because the shrimp farms are excavated and form low spots in the

320 landscape, they are prime areas for sedimentation as currents flow in and pool, especially if

321 mangroves are present to encourage the trapping of sediment particles. If this rapid

322 sedimentation indeed occurred, the theoretical $3 \mathrm{~cm} \mathrm{yr}^{-1}$ of accretion that our results would

323 suggest would rapidly place the high quantities of organic matter in an anaerobic environment 
324 and potentially reduce the rate of decomposition. If this is indeed the case, restoration of shrimp

325 farm plots to mangroves mitigates much of the change that original shrimp farm construction

326 might have caused.

\section{Current Context and Future Concerns}

328 Geographically, our study is unique in that it provides the first estimate of mangrove

329 carbon storage on the Pacific coast of South America. Putting this into a global context, our

330 results are concordant with those published in meta-analyses that synthesize studies mainly from

331 Southeast Asia and Florida (Table 2). Our measurements come from equatorial mangroves, which

332 are thought to be among the highest productivity globally (Alongi 2002).This potential

333 geographical variation should be considered in extrapolations to global mangrove carbon storage.

334 Mangrove restoration is becoming increasingly attractive as we search for ways to

335 mitigate climate change. Though preservation of existing carbon stocks is a clear way to prevent

336 additional

337 emissions from deforestation, restored shrimp farms display even higher carbon standing stocks

338 than mangroves, which are thought to have some of the highest rates globally. It is likely that

339 having mangroves present promotes burial - rather than disturbance and aeration - of the carbon

340 present. Because there are very few studies of mangrove restoration potential in terms of carbon

341 storage, a proper evaluation will require additional studies in other areas where restoration may

342 be a viable option, perhaps with a specific focus on those regions (unlike ours) where

343 monocultures do not occur naturally as well as in restored zones. Long-term monitoring will be

344 needed to verify the continued storage of the carbon peaks we observed. Our study demonstrates

345 the potential for mangrove restoration to effectively sequester carbon.

\section{Acknowledgements}


347 This work could not have been completed without the tremendous help of Katie Dubois, Andrew

348 Chan, Kaitlyn Ferguson, Spencer Scheidt, Andres Ledergeber, Rachel Gittman, Barbara

349 MacGregor, Jack Stanford, and the staff and volunteers at Congal Biomarine Station. Thanks

350 also go to the Jatun Sacha Organization and Diego Quiroga for help establishing a field base.

351 Research was funded in part by a Summer Undergraduate Research Fellowship from the Office

352 for Undergraduate Research at the University of North Carolina at Chapel Hill, and a Watts-Hill

353 Award from the Institute for the Environment at the University of North Carolina at Chapel Hill.

354 John Bruno is the sole owner of The Blue Carbon Project, a start up corporation developed to

355 facilitate mangrove restoration and conservation through the sale of carbon offset credits. 


\section{Literature Cited}

357

358

359

360

361

362

363

364

365

366

367

368

369

370

371

372

373

374

375

376

377

378

379

$<$ NI - 2011 - State of the Science on Coastal Blue Carbon.pdf $>$.

-- UN-Redd Programme - About REDD.

(2012) Climate Change: Evidence, Impacts, and Choices National Research Council, The National Academies.

Allen, S.E. (1974) Chemical analysis of ecological materials. Wiley; [distributed by Halsted Press.

Alongi, D.M. (2002) Present state and future of the world's mangrove forests. Environmental Conservation, 29, 331-349.

Alongi, D.M. (2011) Carbon payments for mangrove conservation: ecosystem constraints and uncertainties of sequestration potential. Environmental Science \& Policy, 14, 462-470.

Alongi, D.M. (2012) Carbon sequestration in mangrove forests. Carbon Management, 3, 313322.

Avnimelech, Y., Ritvo, G., Meijer, L.E. \& Kochba, M. (2001) Water content, organic carbon and dry bulk density in flooded sediments. Aquacultural Engineering, 25, 25-33.

Bouillon, S., Borges, A.V., Castaneda-Moya, E., Diele, K., Dittmar, T., Duke, N.C., Kristensen, E., Lee, S.Y., Marchand, C., Middelburg, J.J., Rivera-Monroy, V.H., Smith, T.J. \& Twilley, R.R. (2008) Mangrove production and carbon sinks: A revision of global budget estimates. Global Biogeochemical Cycles, 22.

Breithaupt, J.L., Smoak, J.M., Iii, T.J.S., Sanders, C.J. \& Hoare, A. (2012) Organic carbon burial rates in mangrove sediments: Strengthening the global budget. Global Biogeochemical Cycles, 26.

Cebrian, J. (2002) Variability and control of carbon consumption, export, and accumulation in marine communities. Limnology and Oceanography, 47, 11-22. 
380

381

382

383

384

385

386

387

388

389

390

391

392

393

394

395

396

397

398

399

400

401

402

403

404

Chmura, G.L., Anisfeld, S.C., Cahoon, D.R. \& Lynch, J.C. (2003) Global carbon sequestration in tidal, saline wetland soils. Global Biogeochemical Cycles, 17.

Clough, B.F., Dixon, P. \& Dalhaus, O. (1997) Allometric relationships for estimating biomass in multi-stemmed mangrove trees. Australian Journal of Botany, 45, 1023-1031.

Couwenberg, J., Dommain, R. \& Joosten, H. (2010) Greenhouse gas fluxes from tropical peatlands in south-east Asia. Global Change Biology, 16, 1715-1732.

Dedysh, S.N., Derakshani, M. \& Liesack, W. (2001) Detection and Enumeration of Methanotrophs in Acidic Sphagnum Peat by 16 S rRNA Fluorescence In Situ Hybridization, Including the Use of Newly Developed Oligonucleotide Probes for Methylocella palustris. Applied and Environmental Microbiology, 67, 4850-4857.

Donato, D.C., Kauffman, J.B., Mackenzie, R.A., Ainsworth, A. \& Pfleeger, A.Z. (2012) Wholeisland carbon stocks in the tropical Pacific: Implications for mangrove conservation and upland restoration. Journal of Environmental Management, 97, 89-96.

Donato, D.C., Kauffman, J.B., Murdiyarso, D., Kurnianto, S., Stidham, M. \& Kanninen, M. (2011) Mangroves among the most carbon-rich forests in the tropics. Nature Geoscience, 4, 293-297.

Duarte, C.M., Middelburg, J.J. \& Caraco, N. (2005) Major role of marine vegetation on the oceanic carbon cycle. Biogeosciences, 2, 1-8.

Ellison, J.C. (2008) Long-term retrospection on mangrove development using sediment cores and pollen analysis: A review. Aquatic Botany, 89, 93-104.

Fourqurean, J.W., Duarte, C.M., Kennedy, H., Marbà, N., Holmer, M., Mateo, M.A., Apostolaki, E.T., Kendrick, G.A., Krause-Jensen, D., McGlathery, K.J. \& Serrano, O. (2012) Seagrass ecosystems as a globally significant carbon stock. Nature Geoscience, 5, 505-509.

Fujimoto, K., Imaya, A., Tabuchi, R., Kuramoto, S., Utsugi, H. \& Murofushi, T. (1999) Belowground carbon storage of Micronesian mangrove forests. Ecological Research, 14, 
406 Giri, C., Ochieng, E., Tieszen, L.L., Zhu, Z., Singh, A., Loveland, T., Masek, J. \& Duke, N.

407

408

409

410

411

412

413

414

415

416

417

418

419

420

421

422

423

424

425

426

427

428

429

(2011) Status and distribution of mangrove forests of the world using earth observation satellite data. Global Ecology and Biogeography, 20, 154-159.

Granek, E. \& Ruttenberg, B.I. (2008) Changes in biotic and abiotic processes following mangrove clearing. Estuarine, Coastal and Shelf Science, 80, 555-562.

Hedges, J.I. \& Stern, J.H. (1984) Carbon and Nitrogen Determinations of Carbonate-Containing Solids. Limnology and Oceanography, 29, 657-663.

Howard, P.J.A. \& Howard, D.M. (1990) Use of Organic-Carbon and Loss-on-Ignition to Estimate Soil Organic-Matter in Different Soil Types and Horizons. Biology and Fertility of Soils, 9, 306-310.

Kauffman, B., Murdiyarso, D., Kurnianto, S., Donato, D. \& Warren, M. Ecosystem Carbon Stocks of Tropical Wetland Forests of the Asia Pacific and Their Fates Following Land Use/Land Cover Change.

Komiyama, A., Ong, J.E. \& Poungparn, S. (2008) Allometry, biomass, and productivity of mangrove forests: A review. Aquatic Botany, 89, 128-137.

Komiyama, A., Poungparn, S. \& Kato, S. (2005) Common allometric equations for estimating the tree weight of mangroves. Journal of Tropical Ecology, 21, 471-477.

Kristensen, E. (2007) Organic carbon dynamics in mangrove ecosystems: a review. Aquatic Botany, 89, 201-209.

Laffoley, D. \& Grimsditch, G. (2009) The management of natural coastal carbon sinks. Iucn. Le Quéré, C., Andres, R.J., Boden, T., Conway, T., Houghton, R.A., House, J.I., Marland, G., Peters, G.P., van der Werf, G., Ahlström, A., Andrew, R.M., Bopp, L., Canadell, J.G., Ciais, P., Doney, S.C., Enright, C., Friedlingstein, P., Huntingford, C., Jain, A.K., Jourdain, C., Kato, E., Keeling, R.F., Klein Goldewijk, K., Levis, S., Levy, P., Lomas, M., 

Discussions, 5, 1107-1157.

433

Lovelock, C.E., Ruess, R.W. \& Feller, I.C. (2011) CO2 Efflux from Cleared Mangrove Peat. PLoS ONE, 6, 1-4.

McLeod, E., Chmura, G.L., Bouillon, S., Salm, R., Bjork, M., Duarte, C.M., Lovelock, C.E., Schlesinger, W.H. \& Silliman, B.R. (2011) A blueprint for blue carbon: toward an improved understanding of the role of vegetated coastal habitats in sequestering $\mathrm{CO} 2$. Frontiers in Ecology and the Environment, 9, 552-560.

Osland, M., Spivak, A., Nestlerode, J., Lessmann, J., Almario, A., Heitmuller, P., Russell, M., Krauss, K., Alvarez, F., Dantin, D., Harvey, J., From, A., Cormier, N. \& Stagg, C. (2012) Ecosystem Development After Mangrove Wetland Creation: Plant-Soil Change Across a 20-Year Chronosequence. Ecosystems, 15, 848-866.

Pan, Y., Birdsey, R.A., Fang, J., Houghton, R., Kauppi, P.E., Kurz, W.A., Phillips, O.L., Shvidenko, A., Lewis, S.L., Canadell, J.G., Ciais, P., Jackson, R.B., Pacala, S.W., McGuire, A.D., Piao, S., Rautiainen, A., Sitch, S. \& Hayes, D. (2011) A large and persistent carbon sink in the world's forests. Science, 333, 988-993.

Pearson, T., Walker, S. \& Brown, S. (2005) Sourcebook for land use, land-use change and forestry projects. Winrock International and the BioCarbon Fund of the World Bank.

Pendleton, L., Donato, D.C., Murray, B.C., Crooks, S., Jenkins, W.A., Sifleet, S., Craft, C., Fourqurean, J.W., Kauffman, J.B., Marbà, N., Megonigal, P., Pidgeon, E., Herr, D., Gordon, D. \& Baldera, A. (2012) Estimating Global "Blue Carbon” Emissions from Conversion and Degradation of Vegetated Coastal Ecosystems. PLoS ONE, 7.

Schlesinger, W.H. (1997) Biogeochemistry: an analysis of global change. Academic press. van der Werf, G.R., Morton, D.C., DeFries, R.S., Olivier, J.G.J., Kasibhatla, P.S., Jackson, R.B., 
455 Collatz, G.J. \& Randerson, J.T. (2009) CO2 emissions from forest loss. Nature

$456 \quad$ Geoscience, 2, 737-738.

457 Wolanski, E. (1995) Transport of Sediment in Mangrove Swamps. Hydrobiologia, 295, 31-42.

458 Young, B.M. \& Harvey, L.E. (1996) A spatial analysis of the relationship between mangrove

459 (Avicennia marina var australasica) physiognomy and sediment accretion in the Hauraki

460 Plains, New Zealand. Estuarine Coastal and Shelf Science, 42, 231-246. 


\section{Figure 1}

Sample collection methods

(A) prop root structure on red mangroves at Site Nat 2; (B) exposed root structures at low tide show accumulation of sediment; (C) field extrusion method: discard of $5 \mathrm{~cm}$; (D) core tube fully submerged in sediment with rubber piston held at the surface of the ground.
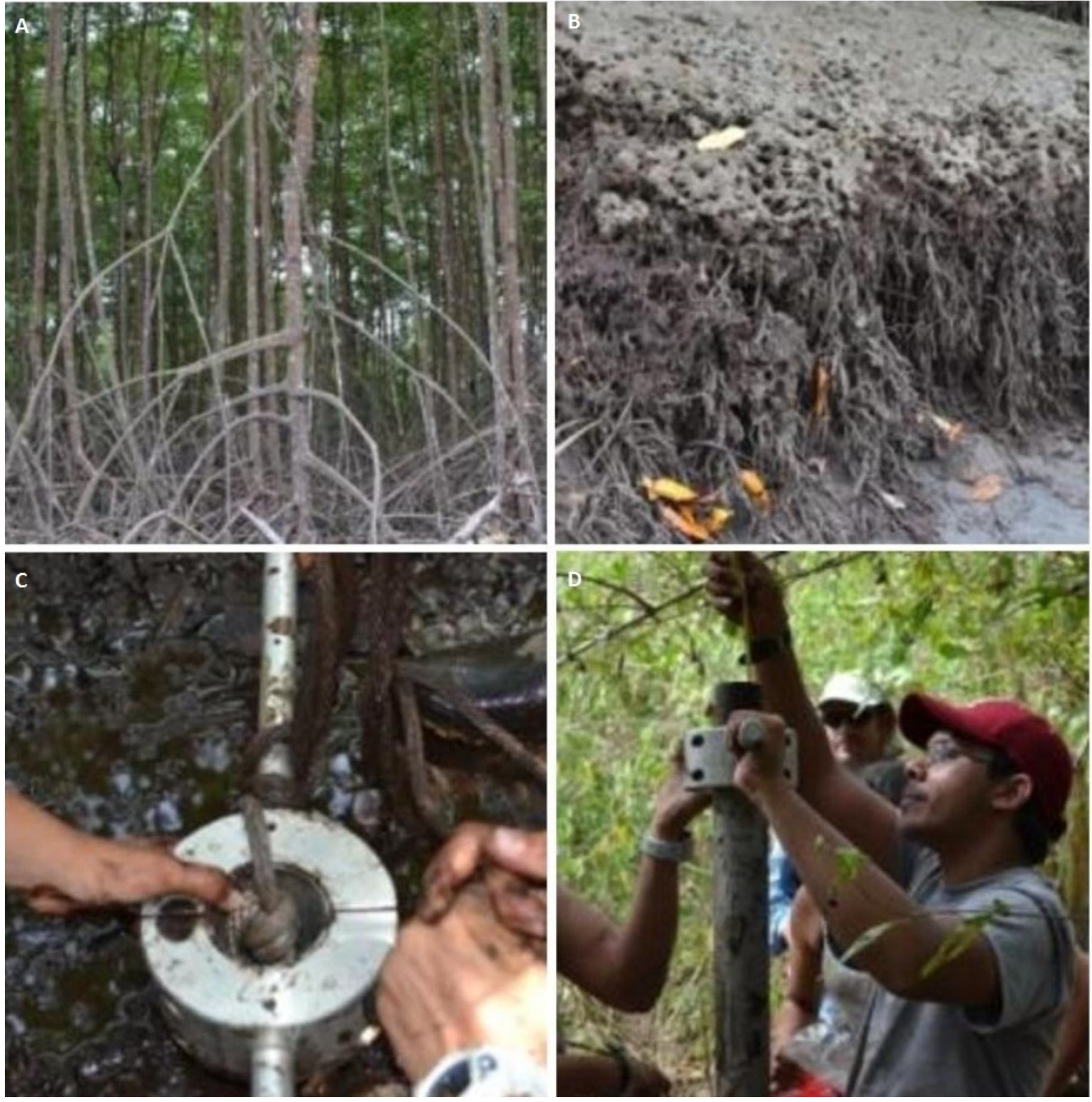


\section{Figure 2}

Loss-on-ignition to percent organic carbon conversion

Comparison of methods used to derive \%TOC values from \%LOI measurements. Studies using LOI as a proxy for TOC have traditionally used the 1.72 conversion factor (red); our data suggest the use of a linear regression (black).

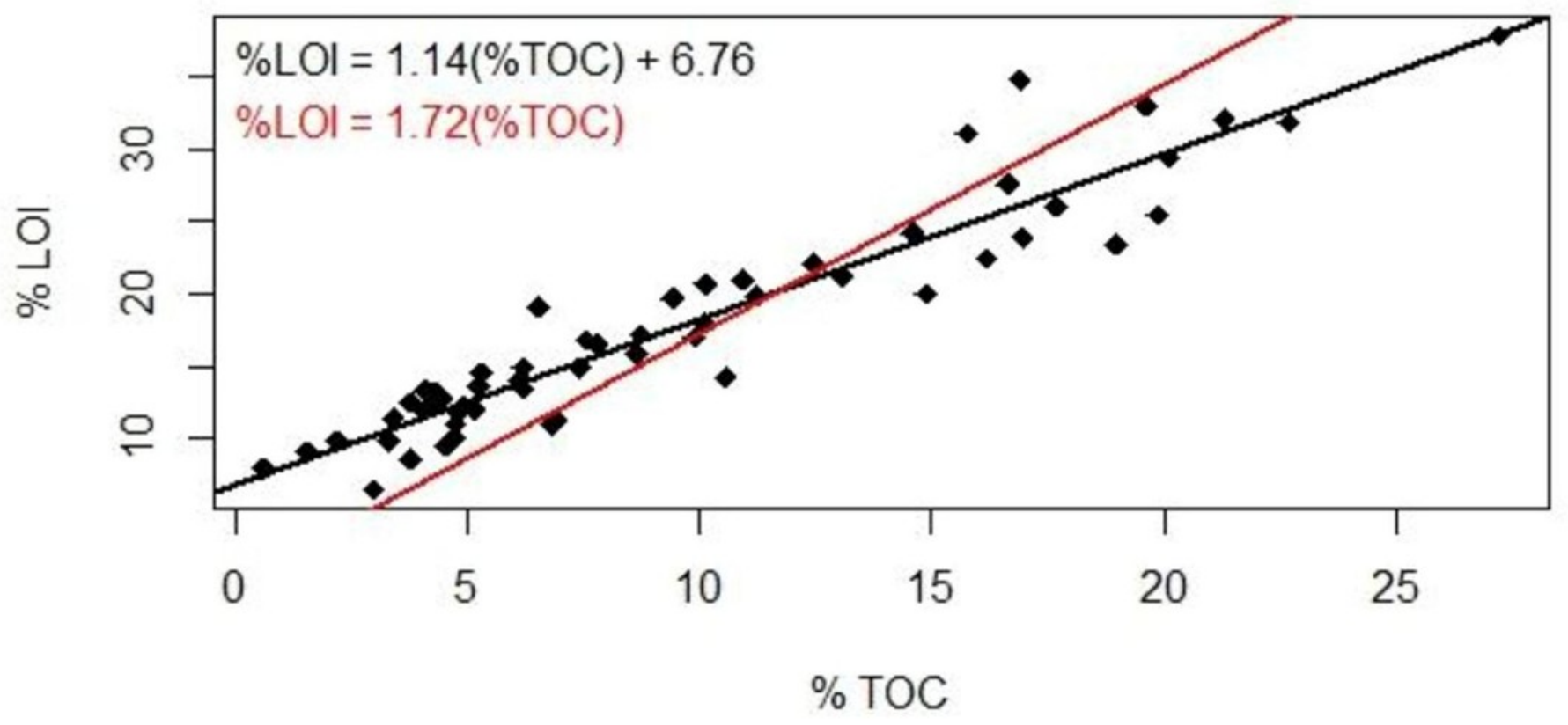




\section{Table 1 (on next page)}

Core sample statistics summarized per site

Summary statistics per site (means \pm standard errors) for a soil depth of $71 \mathrm{~cm}$ (corrected carbon stocks) using both the 1.72 conversion factor and our conversion equation $\left(^{*}\right)$. 


$\begin{array}{llll}\text { Site } & \text { Aboveground } & \text { Sediment Carbon } & \text { Sediment Carbon Storage }\left(\left(\mathrm{Mg} \cdot \mathrm{Ha}^{-1}\right)^{*}\right. \\ & \text { Biomass }\left(\mathrm{Mg} \cdot \mathrm{Ha}^{-1}\right) & \text { Storage }\left(\left(\mathrm{Mg} \cdot \mathrm{Ha}^{-1}\right)\right. & \\ \text { Nat A } & 70 \pm 18 & 448 \pm 143 & 397 \pm 175 \\ \text { Nat B } & 193 \pm 57 & 387 \pm 45 & 356 \pm 63 \\ \text { Nat C } & 39 \pm 11 & 386 \pm 61 & 374 \pm 177 \\ \text { Rest A } & 24 \pm 5 & 427 \pm 54 & 365 \pm 97 \\ \text { Rest B } & 46 \pm 10 & 395 \pm 22 & 321 \pm 71 \\ \text { Aff } & 93.3 \pm 1 & 399 \pm 22 & 304 \pm 67\end{array}$




\section{Figure 3}

Restored and natural site biomass and tree density

Restored sites tended to have higher total trees and lower total biomass estimates than the natural sites. The afforested site overall had fewer trees than either other classification, but more closely resembled the forest structure of the natural sites. 
Biomass (Mg)

Trees (hundreds)

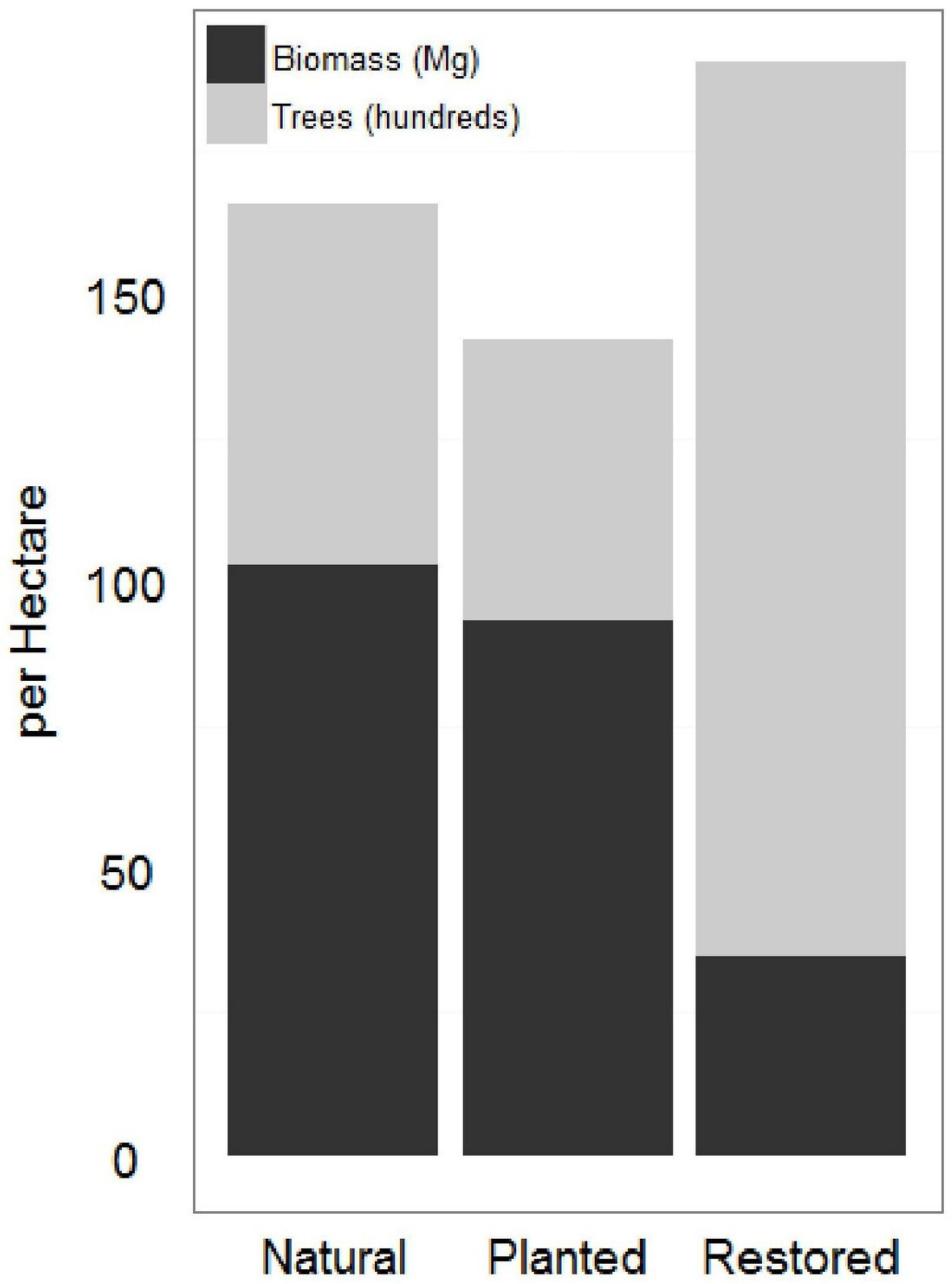




\section{Figure 4}

Total organic carbon vs. bulk density

Inverse relationship between \%TOC and bulk density (Eqn. 2)

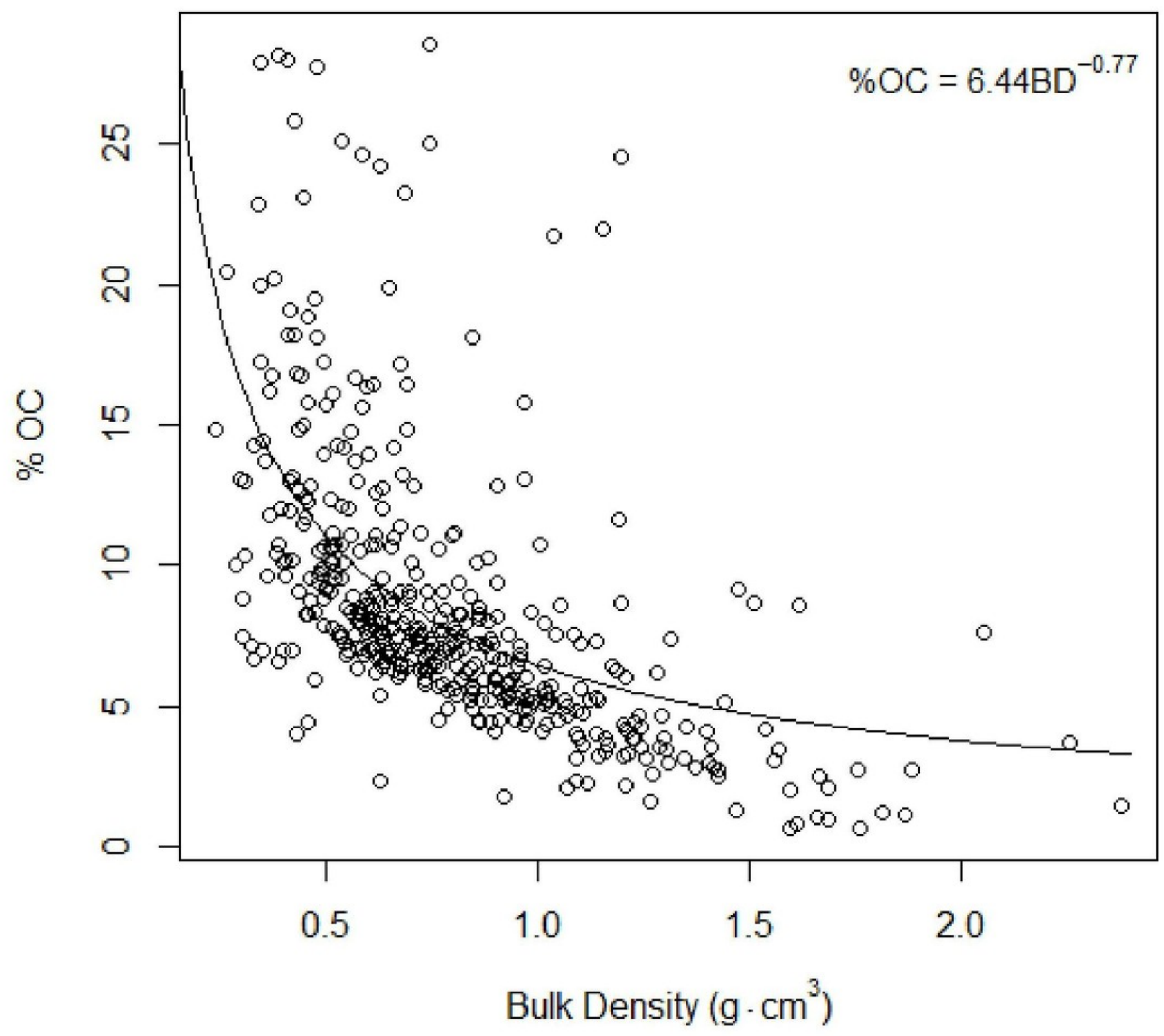




\section{Figure 5}

Total organic carbon profiles of natural and restored sites

\%TOC profiles (means +/- standard error using 1.72 conversion factor) suggest negligible differences between the two main site classifications, but a slight peak in the restored site profile is noted between $40-60 \mathrm{~cm}$ of depth. 


\section{Figure 6}

Carbon density profiles in natural and restored sites

Carbon concentration profiles (means +/- standard error using 1.72 conversion factor) suggest negligible differences between the two main site classifications, but again, a slight peak in the restored site profile is noted between 20 and $60 \mathrm{~cm}$ of depth. 


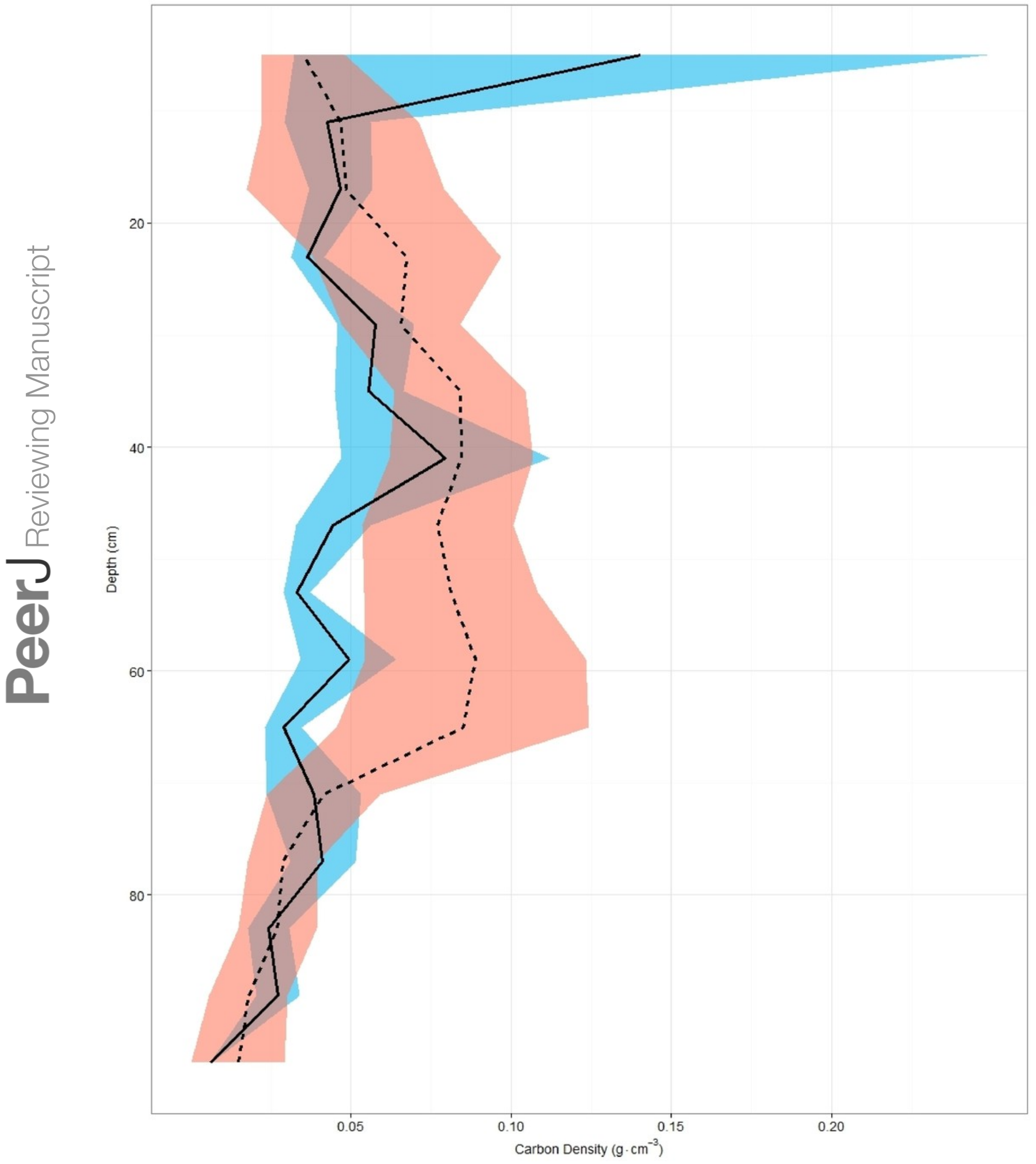




\section{Table 2 (on next page)}

Comparison of carbon storage estimates to global statistics

Comparison of natural and restored site carbon storage estimates to previously published estimates. 
Source

Chmura et al. (2003)

Donato et al. (2011)

Sifleet et al. (2011)

Natural, this study

Restored, this study

Afforested, this study
Region(s)

Mean Soil Carbon

Concentration $\left(\mathrm{g} \mathrm{C} \mathrm{cm}^{-3}\right)$

Global

Indo-Pacific

Global

Ecuador

Ecuador

Ecuador
0.055

0.038 (Estuarine),

0.061 (Oceanic)

$0.015-0.115$

$0.055 \pm 0.002$

$0.058 \pm 0.002$

$0.056 \pm 0.002$
$0.5 \mathrm{~m}$

Variable, up to $3 \mathrm{~m}$

Variable

0.65-1 m

$0.65-1 \mathrm{~m}$

$0.65-1 \mathrm{~m}$ 